\title{
Auricular Defects: Autogenous Vs Prosthetic Reconstruction
}

\author{
Gupta $S^{1}$, Gupta $S^{2}$, Pandey $A^{3}$ \\ ${ }^{1}$ Dr. Shubhankur Gupta, Senior Resident, Department of ENT,Indraprastha Apollo Hospital. New Delhi \\ ${ }^{2}$ Dr. Sugandha Gupta, Post Graduate, Department ofProsthodontics, ManavRachna Dental College, Faridabad \\ ${ }^{3}$ Dr. Anil Pandey, Senior Resident, Department of ENT, BPS Govt. medical college, Khanpur, Sonipat \\ Address for correspondence: DrShubhankur Gupta, Email: shubhankur1407@gmail.com
}

\begin{abstract}
Introduction: Auricular defects and deformities include not only acquired defects attributable to trauma, burns, tumors, piercing defects, scars, and inflammation/allergies, but also congenital auricularmalformations. Methods: Alternatives for auricular reconstruction include autologous costal cartilage graft, prosthetic reconstruction with adhesives and osseointegrated implants. Conclusion: Total auricular reconstruction in patient with auricular defects is one of the most challenging problems faced by a reconstructive surgeon as it demands precise surgical technique combined with artistic creativity. Ear reconstruction requires carefully planned procedures. The use of autogenous rib cartilage is the gold standard for microtia reconstruction. Overcoming the limitations of surgical procedures prosthetic rehabilitation can be done successfully. The purpose of this article is to compare the two procedures and discuss their advantages and disadvantages.
\end{abstract}

Keywords: Auricular defects, Microtia, Graft, Prostheses, Implants.

\section{Introduction}

An auricular defect generally occurs due to congenital abnormalities, trauma from burns, accidental cases, animal attacks or surgical removal of cutaneous malignancies. Microtia is a birth deformity of one or both ears in which the auricle i.e. outer ear is underdeveloped or absent. Microtia is a congenital malformation of variable severity of the external and middle ear[1]. The microtic auricle consists of a disorganized remnant of cartilage attached to a variable amount of soft tissue lobule, which often is displaced from a position symmetrical with the opposite normal ear. The direction of lobule displacement usually depends on the degree of associated facial hypoplasia. Hearing can be affected in microtia because of involvement of external canal and middle ear [2]. Its appearance causes a psychosocial effect on the affected children and their families. Thalidomide and isotretinoin can cause congenital deformities such as microtia. Microtia occurs as an independent anomaly or in association with other syndromes (Goldenhar syndrome and Treacher Collins syndrome). Weerda's classification [2] for auricular malformations is based on an increasing severity of the malformation(Table 1).

Only two treatment options are available:

1. Autogenous reconstruction and

2. Prosthetic reconstruction

Autogenous Reconstruction: The use of autogenous rib cartilage is the gold standard for microtia reconstruction. The origin of microtia repair had started in 1920, when Gillies buried carved homograft rib cartilage under mastoid skin, then separated it from the head with a flap of neck skin [3]. A major breakthrough came in 1959, when Tanzer [4] used autogenous rib cartilage, which he carved in a solid block. Till date, autogenous cartilage is the most reliable material that produces results with minimal complications. Various donor sites (knee, thighs, ribs) have been used for harvesting the cartilage. Rib cartilage provides a substantial source for fabricating a total ear framework. Building upon Tanzer's

Manuscript received: $09^{\text {th }} \mathrm{Feb} 2016$

Reviewed: $20^{\text {th }}$ Feb 2016

Author Corrected: $02^{\text {nd }}$ March 2016

Accepted for Publication: $11^{\text {th }}$ March 2016 
sound principles, Brent [5] refined and evolved the use of rib cartilage and have created frameworks for years. He was the first to report the successful use of tissue expansion in reconstruction of the microtic ear. Rib cartilage has been studied in various parts of the globe include Firmin, Osorno,Nagata, Weerda and Siegert [6-8]. In 1971, Tanzer [4] described a six-stage procedure, modified by Brent and Nagata to a two-stage technique, which is the basis of most current techniques.

Table 1: Weerda's classification based on an increasing severity of the malformation

\begin{tabular}{|c|c|c|}
\hline Degree of dysplasia & Definition & Subgroup \\
\hline $\begin{array}{l}\text { I: Low-grade } \\
\text { malformations }\end{array}$ & $\begin{array}{l}\text { General: most of the structure of a } \\
\text { normal auricle are present } \\
\text { Surgical: additional skin and } \\
\text { cartilage are } \\
\text { only occasionally required for } \\
\text { reconstruction }\end{array}$ & $\begin{array}{l}\text { (i) Prominent auricle } \\
\text { (ii) Macrotia } \\
\text { (iii) Cryptotia (pocket ear) } \\
\text { (iv) Cleft ear (transverse cleft) } \\
\text { (v) Scaphoid ear } \\
\text { (vi) Stahl's ear } \\
\text { (vii) Satyr ear } \\
\text { (viii) Small deformities } \\
\text { (ix) Lobule deformities } \\
\text { (x) Tanzer's types I, IIA, and IIB } \\
\text { cup-ear deformities }\end{array}$ \\
\hline $\begin{array}{l}\text { II: Grade II microtia; } \\
\text { moderate malformations }\end{array}$ & $\begin{array}{l}\text { General: the auricle still displays } \\
\text { some } \\
\text { structure of a normal auricle } \\
\text { Surgical: additional skin and } \\
\text { cartilage required for partial } \\
\text { reconstruction }\end{array}$ & $\begin{array}{l}\text { (i) Tanzers's type III cup-ear } \\
\text { deformity } \\
\text { (ii) Miniear }\end{array}$ \\
\hline $\begin{array}{l}\text { III: Grade III microtia with } \\
\text { anotia; severe } \\
\text { malformations }\end{array}$ & $\begin{array}{l}\text { General: structures of a normal } \\
\text { auricle no longer present Surgical: } \\
\text { additional skin and cartilage } \\
\text { required for total reconstruction }\end{array}$ & $\begin{array}{l}\text { (i) Unilateral Grade III microtia } \\
\text { (ii) Bilateral Grade III microtia } \\
\text { (iii) Anotia } \\
\text { (iv) Normally congenital aural } \\
\text { atresia will be found }\end{array}$ \\
\hline
\end{tabular}

The basic principle of current techniques is the harvesting of the costal cartilage as the first step[7-10].The first stage of the reconstruction surgery is Auricular framework fabrication with help of contra lateral rib cartilage and insertion of cartilage in the skin pocket. Rib cartilages are obtained en bloc from the contra lateral side synchondrosis of $6,7,8$ th ribs for natural rib configuration. The helical rim is fashioned separately with cartilage from the $8^{\text {th }}$ rib. Excision of this cartilage facilitates adequate access to the synchondrotic region of ribs $6 \& 7$ which supplies a sufficient block area to carve the framework body. By preserving even a minimal rim of upper margin of 6 th rib cartilage we can decrease chest wall deformities. Care is taken to preserve as much perichondrium on the various surfaces mainly lateral, outer aspect of the framework to facilitate its adherence \& subsequent nourishment from surrounding tissues. Acute bending of the helical framework is done and this is sutured to the frame work base with the 3-0 or 4-0 prolene suture material in order to exaggerate the helical rim.

Framework implantation: After the creation of the framework of the auricle during the same procedure, it is positioned underneath the skin on the planummastoideum. Preoperative marking of siteand location with upper, lower \& outer limits of snug fit subdermal cavity in right axis is done. By small anterior incision on the auricular vestige with centrifugal skin relaxation, a thin flap is raised by sharp dissection and also by preserving subdermal plexus without making button holes. Native cartilage remnant is excised \&discarded. Absolute hemostasis is done in the snug fit cavity and the cartilage framework implanted inside the skin pocket. Intra operatively the donor site as well as the reconstructed site are managed by negative suction drainage which is removed later in post-operative period. This creates a continuous suction and promotes adherence of the adequately nourished skin flap to the cartilage sculpture and prevents disastrous hematomas. The drains are then removed on the fifth postoperative day, when minimal drainage is observed and the skin is welladhered to the cartilage framework. Sutures are removed from the ear after 5-7 days. 
The second stage surgery includes Auricular framework elevation. At an interval of 3 to 6 months, the 3D projection from the mastoid is formed by elevating the neoauricle from the mastoid and creating a posterior auricular sulcus. Posterior auricular margin is defined by separating the ear from the head and covering its undersurface. Incision is made several $\mathrm{mm}$ behind the rim, so that the graft will not be seen and care is taken to preserve protective connective tissue layer on cartilage framework. The graft is harvested from thigh and usually partial thickness graft was used to cover the raw area and tie over dressing was done to maintain the proper cephaloauricular angle.

The third stage involves lobule transposition: The rotation or reposition of lobule is essentially done by z-plasty transposition. A third stage is necessary for the fine tailoring of the contours of the auricle.

Prosthetic Reconstruction: The fabrication of auricular prosthesis is considered as one of the most difficult replacements in maxillofacial reconstruction by the prosthodontists. The severe undercuts and pronounced convolutions of the ear's surface pose a challenge to be simulated by a prosthesis [11-13].

Two major problems in making prosthetic ear are reconstructing an exact copy i.e mirror-image prosthetic ear and orientation of the prosthesis in the exact location to the surrounding tissues. These problems can be solved by making a free hand carved pattern of the ear in a modeling wax and simulating it to the natural one not only in form but also texture and orienting it correctly to the surrounding tissues [12,13]. The conventional basic procedure in the fabrication of auricular prosthesis involves the impression of the defect and non-defect ear with irreversible hydrocolloid followed by pouring of impression in high strength dental stone. Wax sculpture of the defective ear is made using modeling wax and trial is done on patient and corrections are done according to the contours, visibility, height, width, and according to patient's expectations. Molds are made to fabricate silicone prosthesis for the patient. These prosthesis can be retained by the use of adhesives, emulsions, spray-ons, tapes but retention was the problem with these adhesive systems. Another adoptable method is attaching prosthesis to spectacles or hair bands, but inadvertent displacement or detachment are disadvantageous in retention of prosthesis.

A breakthrough in the retention of the auricular prosthesis occurred when Branemarkin 1980's introduced osseointeg rating implants [11]. Implants body or fixtures for ear prosthesis are made of biocompatible titanium metal alloys and placed in the mastoid bone. The implant retained auricular prosthesis system has three parts - Theosseointegrated implant, the retention system and the prosthesis. Size of an implant is determined by the thickness of the bone involved. A two-stage surgery is suggested for the osseo-integrating implants. As per the accepted protocol, the implants are placed in the mastoid region area $15 \mathrm{~mm}$ apart keeping a distance of $20 \mathrm{~mm}$ from auditory canal opening. After osseointegration verification radiographically (in a period of 3-4 months) the second surgery is done to place the abutment. After osseointegration of the implant (3-4 months period), percuteneous abutments are connected which can hold the prosthesis. The prosthesis is mechanically retained either by using embedded clips or magnets. Implant-retained prostheses offer good aesthetics, close fit to the body and the convenience of easy removal and refitting.

\section{Discussion}

The choice between the two remaining techniques, autogenous reconstruction and prosthetic reconstruction, depends more critically on the surgeon's skills, training and tradition than on an analysis of which procedure is preferable in a given clinical situation. In the hands of an experienced surgeon, who performs the procedure on a regular basis, autogenous techniques yield consistent results. The indication for reconstruction with autologous rib cartilage depends on the nature, severity and extent of the auricular deformity and on the patient[4].Starting at the age of 8 to 9 years, it is a good option in children. At this age, enough cartilage can be compliantly harvested to complete the procedure. Autogenous ear reconstruction has the disadvantage that a suboptimal result might be uncorrectable[10].Prosthetic reconstruction of the auricle is considered in such patients with congenital deformities for the following indications include failed autogenous reconstruction, severe soft-tissue/skeletal hypoplasia, and/or a low or unfavorable hairline, acquired total or subtotal auricular defect, most often traumatic or ablative in origin, which is usually encountered in adults, patient's preference and cost factor[5-10]. 
Earlier, ear prostheses were not well tolerated because of the inconvenience and ineffectiveness of chemical adhesives [12,13]. Osseointegration, the direct structural connection between living bone and a implant, has reduced the problems of prosthesis retention and inconvenience[11]. Advantages of autogenous reconstruction over prosthetic rehabilitation are evident. Once an autogenous reconstruction is completed, the patient requires no further treatment. In contrast, prosthetic reconstruction requires replacement of the prosthesis every 2 to 5 years for the life of the patient. Patient with prosthetic ear remains in psychological trauma to wear the prosthesis while autogenously reconstructed auricle can be better accepted. As with any surgical procedure there are risks with autogenous reconstruction which cannot be overlooked. Complications of the procedure can be post-operative infection and cartilage exposure, surgical emphysema leading to donor site complications, hair bearing skin over the auricle can be seen, graft failure, necrosis of graft [4,5]. Prosthetic rehabilitation avoids all these complications [12]. Aesthetics of the rehabilitated auricle depends on skills of the surgeon and prosthodontist. Cost of the prosthetic rehabilitation is far lower than autogenous reconstruction.

\section{Summary and Conclusion}

The field of auricular reconstruction remains a great challenge to facial reconstructive surgeons. The method of choice for reconstruction depends not only on the patient's pathology and the state of the local tissue and skin, but also on the preferences of the facial surgeon and the patient. Various possibilities of reconstruction exist, such as autologous rib cartilage or prosthetic restoration. The choice between the two techniques, autogenous reconstruction and prosthetic reconstruction, depends more on the surgeon's training and patient's preference. Recently, interest in the prefabrication concept has been developed via modern tissue engineering techniques in which bovine cartilage tissues are grown in the laboratory and seeded upon a synthetic ear from which is then implanted beneath the skin of a mouse[14-16]. The early experimental results are interesting, but, it needs a long time of effort and work before it can be applied to humans.

Funding: Nil, Conflict of interest: None. Permission of IRB: Yes

\section{References}

1. Reinisch, J. Microtia reconstruction using a polyethylene implant: An eight year surgical experience. Presented at the 78th Annual Meeting of the American Association of Plastic Surgeons, Colorado Springs, Colo., May 5, 1999.

2. Weerda H.Reconstructive surgery of the auricle.Facial Plast Surg. 1988 Oct;5(5):399-410.

3. Tanzer RC. Total reconstruction of the auricle.The evolution of a plan of treatment.PlastReconstr Surg1971; 47(6):523-33. PMID: 5088649

4. Tanzer RC. The constricted (cup and lop) ear.PlastReconstr Surg1975; 55(4):406-415.PMID: 1118500

5. Brent B.The correction of mi-rotia with autogenous cartilage grafts:

The classic deformity.?PlastReconstr

Surg. 1980

Jul;66(1):1-12.

6. Firmin F. Ear reconstruction in cases of typical microtia. Personal experience based on 352 microtic ear corrections. ScandJPlastReconstrSurg Hand Surg 1998;32(1):35-47.PMID: 9556819

7. NagataS. Modification of the stages in total reconstruction of the auricle: part I. Grafting the threedimensional costal cartilage framework for lobule-type microtia. PlastReconstrSurg 1994;93(2): 221-230.

8. Chauhan DS, Guruprasad Y. Auricular Reconstruction of Congenital Microtia Using autogenous Costal Cartilage: Report of 27 Cases. J Maxillofac Oral Surg. 2012 Mar; 11(1): 47-52.doi: 10.1007/s12663-011-0290-1.

9. Letterman GS, Harding RL. The management of the hairline in ear reconstruction.Plast.Reconstr. Surg. 1956; 18(3):199-207.PMID: 13370369

10. Yotsuyanagi T, Yokoi K, Nihei Y, Sawada Y. Management of the hairline using a local flap in total reconstruction for microtia.PlastReconstr Surg. 1999 Jul;104(1):41-7.

11. Tjellström. A, Rosenhall. U, Lindström. J, Hallén. O, Albrektsson., Brånemark P.I. Five-year Experience with Skin-penetrating Bone-anchored implants in the Temporal bone. ActaOtolaryngol 1983; 95(5-6): 56875. 
12. Brown KE.Fabrication of ear prosthesis.J Prosthet Dent. 1969 Jun;21(6):670-6.

13. Wang R. Preoperative auricular wax pattern duplication for surgical template fabrication. J Prosthet Dent 1999;81:634-7.

14. Green WT Jr, Dickens DR.Culture model for investigation of cartilage matrix formation.Surg Forum. 1972;23(0):453-5.
15. Bomhard, J. Veit, Bermueller C et al. Prefabrocation of 3D cartilage constructs: towards a tissue engineering auricle- a model tested in rabbits," PLoS ONE 2013;8,(8) Article ID e71667.doi:10.1371/journal.pone.0071667

16. Bichara DA, O'Sullivan NA, Pomerantseva I, Zhao $\mathrm{X}$, Sundback CA, Vacanti JP, Randolph MA.The tissueengineered auricle: past, present, and future.Tissue Eng Part B Rev.2012 Feb;18(1):51-61. doi: 10.1089/ten.TEB.2011.0326. Epub 2011 Oct 4.

\section{How to cite this article?}

Gupta S, Gupta S, Pandey A. Auricular Defects: Autogenous Vs Prosthetic Reconstruction. Int J Med Res Rev 2016;4(3):387-391. doi: 10.17511/ijmrr.2016.i03.18 